the society at large but within its framework. In short, the demand that the American Physical Society should shun undesirable activities is unrealistic, but it could usefully provide a forum for discussion of issues like these.

\section{Lord Rank's legacy}

THE Nobel Foundation has done wonders, in the past half century, in providing a modern substitute for the old system by means of which monarchs would reward distinguished scientists with pensions enabling them to continue their work or to live above the poverty line in old age. On the whole, most Nobel prize winners have been eminently deserving of the honour and the reward, with the result that the institution of Nobel prizes has been a useful extra spur to competitiveness. To be sure, there have also been some less desirable consequences. The fact is that the Nobel Foundation's choices are almost inevitably less catholic than they might be. If most prize winners are deserving, not all deserving scientists seem to catch the eyes of the selection committees. It is, after all, a long time since an astronomer was awarded a Nobel prize (although Professor H. Alfven's prize in 1970 was in part a recognition that some of his distinguished work has contributed in important ways to astrophysics and cosmology). So far, no radio astronomer has been honoured, although Professor C. H. Townes has turned to radio astronomy since his prize was awarded in 1964. Nor has there been, as yet, a recognition of the way in which geophysics has been transformed by those who have contributed to what is now the theory of plate tectonics. The result is that in spite of the diligence with which the Nobel commitiees set about their work, the results appear arbitrary in many ways. To complain at this may seem churlish, but it is clear that a scientist on whom the Nobel accolade has not fallen need not be ashamed to look his colleagues in the eye.

In circumstances like these, it is understandable that several charitable organizations should have sought to supplement what the Nobel Foundation does by setting up prize funds in special fields. In the United States, there are now handsome prizes for those who distinguish themselves in nuclear eneigy. Other foundations have tried to provide handsome prizes for engineers and technologists, consistently undervalued by the Nobel committees. The most recent step in this direction has been the generous bequest by the late Lord Rank which will provide a prize fund for those who work in human nutrition and in what is called optical electronics. By all accounts, the precise way in which the Rank fund will operate remains to be decided by the trustees and the two advisory committees. At current interest rates, there may be as much as $£ 100,000$ to spend each year. One of the most important decisions to be made is how much of the available income will be spent on prizes and how much will go on scholarships and fellowships. The first thing to be said is that human nutrition has not been entirely neglected by the Nobel Foundation, for Dr Norman Borlaug was awarded a Nobel prize in 1970 (admittedly for peace and not for science) for his work on the breeding of new strains of wheat and rice. The second is that the fields which have been chosen are so comparatively narrow that it will be hard for the selection committees to find prize winners of a distinction comparable with that of most Nobel prize winners in each year of the operation of the fund. This is why it is to be hoped that the fund will concentrate chiefly on fellowships and other more familiar methods of encouraging worthwhile research. If there are to be prizes, they should be few and far between.

The question remains whether scientists in any discipline should be the sole recipients of the money which the committees hand out. After all, the sums involved are often so large that the unavoidable arbitrariness of the prize-giving process must necessarily be a cause of discontent among close colleagues. Moreover, the recipients of large money prizes are often the first people to acknowledge that their success in research is in part at least dependent on their colleagues and on the institutions in which they work. So is there not a case for asking that if the new Rank fund decides that money prizes should be an important part of its expenditure, these should be given not to deserving people but to the institutions at which they work? And is there not a case for asking that the Nobel Foundation itself should follow suit?

\section{Years Ago}

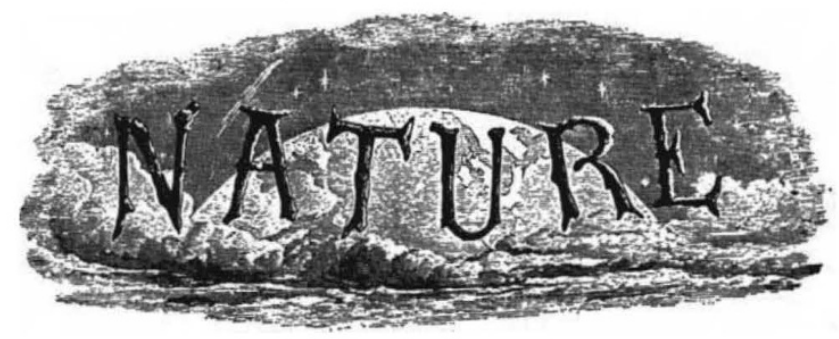

Error in Humboldt's Cosmos

I $B E G$ to call the attention of geometers to what appears to me to be an inaccuracy in a work, which is, perhaps, the last which one would suspect to be capable of error-the "Cosmos" of Humboldt.

In vol. i. p. 293, he says, "I have found by a laborious in. vestigation, which, from its nature, can only give a maximum limit, that the centre of gravity of the land at present above the level of the ocean is, in liurope, 630 ; in N. America, 702 ; in Asia, 1,062; and in S. America, 1,080 French feet (or 671, 748, I, I32, and 1, 151 English feet) above the level of the sea." Sir John Herschel in his "Physical Geography" (Encylop. Britt.) quotes these numbers of Humboldt as giving the height of the centre of gravity of these continents ; and adds, "whence it follows, that the mean elevation of their surfaces (the doubles of these) are respectively $1,342,1,496,2,264$, and 2,302." Herschel's conclusion is, of course, just, if Humboldt meant what he seems to say. But at the risk of being thought most presumptuous, I submit that Humboldt meant the height of the centre of gravity of the surface of the land; in other words, the mean height of the land; and by thus misleading Sir John Herschel he has by a coup de plume doubled all our continents.

I conclude, therefore, with the greatest deference, that Humboldt's "centre de gravité du volume" is an inaccurate expression, and that he meant "centre de gravité de la surface," or mean height. If this be so, Sir John Herschel has Jbeen led into the error of doubling our continents, which he estimates at a mean elevation of 1,800 feet.

It is a matter of some importance; for Sir Charles Lyell computes that the continent of $N$. America will be utterly washed away into the ocean by the ordinary processes of degradation in four and a half millions of years. If, indeed, this period is to be doubled, we can take a more cheerful view of the future of that continent. But I greatly fear with Sir Charles that it is limited to four and a half millions of years, unless some upheaval of the land shall protect its short span of existence.

I13, Eaton Square, March 28 JOHN CARRICK MOORE

From Nature, 5, 479, April 18, 1872. 